\section{BIBLIOTECÁRIO E EDITORAÇÃO: mercado e competências necessárias}

\author{
Maria Giovanna Guedes Farias" \\ Juliana Soares Lima* \\ Francisco Edvander Pires Santos ${ }^{\text {*tox }}$
}

RESUMO As impressões laborais vivenciadas no fazer docente, na experiência de conduzir um periódico científico eletrônico e na prática bibliotecária obtida no processo editorial no Sistema Eletrônico de Editoração de Revistas (SEER), aliadas à revisão de literatura, permitiram a produção deste artigo com o objetivo de apresentar as áreas de atuação do bibliotecário no mundo da editoração e as competências técnicas e comportamentais necessárias para tal. A presença do bibliotecário no mercado editorial tem sido percebida, principalmente, em periódicos científicos e em editoras comerciais e universitárias, mas de forma ainda muito modesta. Ainda são poucos os bibliotecários que atuam na editoração, o que pode ocorrer devido à falta de conhecimento por parte do mercado editorial das diversas competências que esse profissional desenvolve durante a graduação, as quais podem ser um diferencial para uma empresa/instituição editorial. Esse profissional pode atuar na análise de provas editoriais, na assessoria aos editores, autores e pareceristas, na consultoria e avaliação técnica de revista para inclusão em bases de dados, catalogação na fonte, conferência da terminologia e indexação, elaboração de diferentes relatórios relacionados aos periódicos, além de muitas outras áreas. Para isso, precisa desenvolver competências técnicas, tais como: conhecimento do fluxo editorial, de indexadores, diretórios e bases de dados; saber correlacionar a linguagem do autor com os vocabulários controlados existentes; ter capacidade de análise e síntese; conhecer softwares de design e artes gráficas; ter domínio de normalização, ferramentas para gerenciamento de referências e padronizações em publicações editoriais, entre outras tantas; além de competências comportamentais, a exemplo de: assertividade; autonomia; concentração; criatividade; diligência; dinamismo; imparcialidade; inteligência emocional; liderança; motivação; organização; proatividade; relacionamento interpessoal e senso estético.

Palavras-chave: Editoração. Bibliotecário. Áreas de atuação. Competências técnicas e comportamentais.

\footnotetext{
* Doutora em Ciência da Informação pela Universidade Federal da Bahia, Brasl. Docente no Programa de Pós-Graduação em Ciência da Informação da Universidade Federal do Ceará, Brasil.

E-mail: mgiovannaguedes@gmail.com.

** Mestranda no Programa de Pós-Graduação em Ciência da Informação pela Universidade Federal do Ceará, Brasil. Bibliotecária da Universidade Federal do Ceará, Brasil.

E-mail: julialObr@gmail.com.

*** Mestrando no Programa de Pós-Graduação em Ciência da Informação pela Universidade Federal do Ceará Brasil. Bibliotecário da Universidade Federal do Ceará, Brasil.

E-mail: edvanderpires@gmail.com.
}

\section{INTRODUÇÃO}

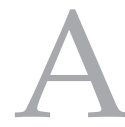

história da editoração tem seu marco consolidado no século XV com o alemão Johannes Gutenberg, ao criar tipos móveis de metal reutilizáveis, revolucionando, assim, a história da impressão ao imprimir a Bíblia. Além disso, essa descoberta impulsionou sucessivos avanços e proporcionou a comercialização do conhecimento em suportes diversos, como livros, jornais e folhetins, democratizando e popularizando a leitura. 
Outras experiências nessa área já existiam há diversos séculos na China, país onde houve a invenção do papel, da xilogravura e de diversas outras formas de impressão, inclusive a tecnologia de impressão com tipos móveis feitos de argila e madeira. Entretanto, foi pelas mãos de Gutenberg que a tipografia ficou conhecida.

Desde os tempos mais remotos, e dependendo do produto que se deseja criar, todo processo de produção editorial requer o envolvimento de diversos profissionais, e um deles é o bibliotecário, o qual pode atuar desenvolvendo uma série de atividades além do que comumente lhe é atribuído, ao se pensar em editoração, a exemplo da normalização, indexação e gestão de bases de dados. Há outros nichos que requerem as competências técnicas e comportamentais do bibliotecário, as quais estão descritas no decorrer deste artigo, construído com base na vivência da prática cotidiana do ensino da disciplina Editoração no curso de Biblioteconomia, assim como pela experiência na criação e edição de um periódico científico da área, trabalho que permite experimentar teorias e hipóteses de atividades que o bibliotecário pode desenvolver no campo editorial.

Destarte, trata-se de uma revisão de literatura, para a qual seguimos as etapas propostas por Hohendorff (2014), quais sejam: definição e delimitação de um tema de pesquisa; busca e organização de materiais para a revisão de literatura; e elaboração do roteiro do artigo. Definimos e delimitamos o tema de interesse, 'bibliotecário e editoração', e constatarmos, na etapa de busca e organização de materiais, a escassez de publicações em Biblioteconomia e Ciência da Informação sobre o assunto. A pesquisa por essas publicações surgiu da necessidade de embasamento teórico para ministrarmos a disciplina de Editoração, mais especificamente entre os anos de 2014 e 2017. A partir disso, elaboramos o roteiro que nos conduziu às seções deste artigo, a saber: editor e editoração; mercado editorial: áreas de atuação e atividades possíveis; e competências do bibliotecário para atuar na editoração.

Nesse sentido, as impressões laborais vivenciadas in loco, ou seja, tanto em sala de aula quanto na arquitetura e estrutura de uma revista científica disponibilizada no Sistema Eletrônico de Editoração de Revistas (SEER), complementaram as etapas da revisão de literatura, uma vez que ambas as experiências nos permitiram construir um quadro de competências voltado para bibliotecários que atuam ou pretendem atuar no mundo da editoração. Obviamente que, ao observar de onde se fala, de onde provêm os discursos e as reflexões aqui explanadas, apresentamos, sobremaneira, a editoração eletrônica, pois nossa experiência se pauta no processo editorial de um periódico digital.

\section{EDITORAÇÃO E EDITOR}

Ao pensarmos no conceito do termo editoração, somos remetidos ao fazer do editor e às fases do processo de produção e publicação de livros, revistas, cadernos, prospectos e uma infinidade de outros produtos editoriais; contudo, trata-se de uma tarefa mais ampla. Aliás, conforme Martins Filho (2016), a editoração - ou edição - é uma atividade antiga, proveniente desde os primeiros livros em rolo, perpassando por Timão, o filósofo cético (320 a.C. - 230 a.C.), leitor, copista e comentarista das obras da Biblioteca de Alexandria; e Zenódoto, o primeiro bibliotecário da instituição referida anteriormente, que lia, copiava e fazia intervenções nos textos de Ilíada e Odisseia, colocando, assim, suas edições sob suspeita. $\mathrm{Ou}$ seja, em tempos remotos, a arte da edição não estava restrita apenas ao registro e às cópias dos manuscritos existentes, mas também para a preservação destes e, consequentemente, para tornar públicos os textos. Martins Filho (2016) esclarece que essa perspectiva explica o conteúdo semântico original do latim editor, como quem gera e produz.

A revolução de Gutenberg e seus tipos móveis "[...] intensificou ainda mais a oposição entre a escrita (= original) e o texto (= impresso), na medida em que a possibilidade de reprodução mecânica do livro exigiu novos níveis de profissionalização e de padronização" (MARTINS FILHO, 2016, p. 12). Para esse autor, os editores sobreviveram a todas as revoluções que incidiram sobre a cultura escrita, como a passagem do rolo ao códice, a invenção da imprensa e a emergência do texto digital. Isto é, ao longo do tempo, variadas técnicas tornaram-se úteis para produzir materiais gráficos, inclusive, com o advento da internet e dos computadores, 
surgiu a editoração eletrônica (CAMPOS, 2016), tarefa que trouxe novas técnicas e formas de se produzirem peças gráficas.

Em 1986, Araújo afirmou que a editoração, no âmbito restrito da produção de livros, pode ser definida como o "[...] conjunto de tarefas do editor, que consistem basicamente em supervisionar a publicação dos originais em todo o seu fluxo pré-industrial (seleção, normalização) e industrial (projeto gráfico, composição, revisão, impressão e acabamento)". Segundo Cunha (1982) a palavra 'editor' surgiu na Roma Antiga para identificar aqueles que assumiam a responsabilidade de multiplicar e de cuidar das cópias dos manuscritos originais dos autores, com o objetivo de que fosse correta a sua reprodução; por isso, o termo editor indica "dar à luz" e "publicar". Para Bragança (2005) o editor de texto precisa, primeiramente, ler os originais, a fim de observar a harmonia do estilo, da distribuição do conteúdo e da linguagem, a adequação das ilustrações, anotar as lacunas, as necessidades, as divergências e as particularidades gráficas da obra.

Por volta de 1830, a figura do editor enquanto profissional, segundo Chartier (1999, p. 50), foi construída tal qual conhecemos. "Trata-se de uma profissão de natureza intelectual e comercial que visa buscar textos, encontrar autores, ligá-los ao editor, controlar o processo que vai da impressão da obra até sua distribuição". Para Chartier (1999), o sucesso de um editor não depende se ele tem uma gráfica ou uma livraria, mas sim da sua capacidade de inventividade pessoal e do potencial de cada obra e de cada autor, com o qual estabelece uma relação, por vezes, conflitante, pois são os editores quem:

[...] decidem que textos vão ser transformados em livros. $E$, pensando em qual público a que devem servir, como serão feitos esses livros. Mesmo quando não é deles a iniciativa dos projetos, é deles que parte a direção a seguir. É neste lugar de decisão e de comando, e de criação, que está o coração do trabalho de editor. É também esse lugar que exige dele saberes específicos (escolher, fabricar, distribuir), que $\circ$ diferenciam dos demais agentes envolvidos no processo editorial, e lhe impõe responsabilidades únicas, profissionais, sociais, econômicas, financeiras, administrativas e mesmo (juntamente com os autores) judiciais. (BRAGANÇA, 2005, p. 224).

Podemos, então, defender que o editor é um mediador entre o autor do manuscrito e o leitor. É quem dá forma à publicação e, dependendo da editora, pode tornar uma obra publicável, conhecida ou até mesmo esquecida. Conforme Martins Filho (2016, p. 12), “[...] os editores são os verdadeiros guardiões de uma longa linhagem de leitores benfazejos que zelam pela preservação e publicação dos textos".

A fim de entender melhor todos os conceitos relacionados à atividade da editoração tal como a conhecemos nos campos da Biblioteconomia e Ciência da Informação, principalmente ligada à tarefa da produção de livros e periódicos impressos ou eletrônicos, é necessário esmiuçar as definições oriundas da Comunicação (Jornalismo, Publicidade e Propaganda), das artes gráficas e design gráfico, por se tratarem dos campos de conhecimento especializados no assunto.

As artes gráficas podem ser definidas, segundo a Associação dos Designers Gráficos (2000, p. 13), como "[...] o conjunto de processos e atividades auxiliares que visam reproduzir, em qualquer número de cópias, escritos e imagens a partir de uma matriz. Abrange criação, préimpressão, impressão e acabamento de qualquer material gráfico". Dentro das artes gráficas, o processo da produção gráfica pode ser conceituado de duas formas: organizar e supervisionar a realização de peças gráficas; e em uma agência de publicidade ou empresa editorial, é uma área responsável pela produção e relacionamento com os fornecedores gráficos (ASSOCIAÇÃO DOS DESIGNERS GRÁFICOS, 2000).

A edição, por sua vez, constitui-se num processo de planejamento, envolvendo textos e imagens para compor uma publicação e design editorial (LOPES, 2013). O autor explica que os produtos de design editorial, por conterem mensagens visuais e textuais, devem ser ordenados a fim de cumprirem os objetivos de comunicação: hierarquia da informação, ritmo e harmonia da composição. Já o designer editorial, como explica Villas-Boas (1999, p. 17), é considerado um profissional responsável por organizar "elementos visuais, que são reproduzíveis e que têm um objetivo expressamente comunicacional". 
Em relação ao projeto gráfico, Baer (1999) e Oliveira (2002) ressaltam que compreende a etapa da preparação e a análise prévia antes da confecção de qualquer material impresso ou eletrônico. De acordo com os autores, configura-se como uma etapa importante para dar seguimento às demais fases, tais como o briefing, o rascunho, o layout e a diagramação, pois são estes os processos e as etapas que compõem a editoração. Para a Associação dos Designers Gráficos (2000, p. 88), o projeto gráfico pode ser definido como o "planejamento das características gráfico-visuais de uma peça gráfica, [...] como o formato de papel, processos de composição, impressão e acabamento".

Para se produzir essa peça gráfica, é necessário cumprir as seguintes etapas, especificadas por Baer (1999), Fernandes (2003) e Oliveira (2002): briefing (especificação das principais informações sobre o produto ou serviço); rough (discussão das ideias e planejamento da peça gráfica, por meio da produção de um esboço ou desenho simples); layout (confecção da peça gráfica para análise e aprovação do cliente); arte final (se aprovado o layout, esta etapa corresponde à montagem e preparação do arquivo); pré-impressão (compreende a etapa da avaliação da qualidade do arquivo, tipos de fontes, cores, atendimento às normas técnicas, quando assim o exigir, entre outros detalhes); impressão (nessa etapa, os arquivos da pré-impressão podem ser impressos em um fotolito, que são como negativos de uma fotografia, o boneco ou a prova da artefinal do material); e acabamento (cortes, refile, dobras, aplicação de vernizes, grampeamento, encadernação etc.). Enfatizamos que nem todas as etapas discriminadas acima são executadas na editoração eletrônica, na qual o fotolito tem sido gradativamente substituído por processos informatizados.

Em síntese, a produção gráfica é uma atividade ou setor responsável por realizar a viabilização e o acompanhamento na confecção de matrizes, impressão e acabamento de peças gráficas. Além disso, é responsável por se relacionar com os fornecedores de serviços ligados à produção de peças gráficas (composição, editoração, fotolitos, gráficas, fotógrafos, ilustradores, entre outros). Esse cenário é terreno dos produtores gráficos, mas é também espaço de atuação de bibliotecários que exercem suas atividades no ramo da editoração ou no mercado editorial de livros e periódicos, por exemplo.

Consideramos que o produtor gráfico/ designer editorial deve ter características próprias para o exercício dessa função. Isso requer organização, disciplina, boa comunicação, capacidade técnica e inteligência emocional em tomadas de decisões, conhecimento do mercado e disponibilidade para aprender. Para Lopes (2013, p. 23) o "designer editorial é uma profissão multidisciplinar que atua na formação de opinião e na busca de soluções para um determinado problema gráfico, conjugando características formais com aspectos de funcionalidade do projeto". O autor afirma ainda que a editoração pode atuar em projetos gráficos variados (livros, revistas, jornais, catálogos, entre outros), por ser um campo que congrega de produções advindas de diversas disciplinas; por isso, "o designer deve ter o conhecimento de aspectos culturais e técnicos do projeto, exigindo senso estético e treinamento no manuseio de ferramentas gráficas". (LOPES, 2013, p. 23).

Outra área voltada para o desenvolvimento de projetos com ênfase na disseminação da informação em produtos e serviços é a de design da informação. Além de ser uma área de atuação no desenvolvimento de projetos gráficos, de acordo com a Sociedade Brasileira de Design da Informação (2018, online), é uma área que reúne pesquisadores, docentes e profissionais da área de design, que atuam em sistemas de informação e comunicação analógicos e digitais, na gestão e produção da informação, otimização dos processos de aquisição e gerenciamento da informação visual.

Outro conceito bastante presente na editoração é a diagramação, a qual, segundo Horie e Pereira (2004), deve ser utilizada como elemento importante para guiar a leitura. Os autores apresentam técnicas para identificar as áreas de uma página, como a área principal, área secundária, áreas mortas, centro óptico e centro geométrico, além de outros detalhes importantes na construção da peça gráfica. Na diagramação, para a disposição ordenada de elementos, tais como formas, cores, ilustrações, fotografias e a escolha do formato do texto, é comum a aplicação de um grid, uma espécie de grade, utilizada pelo diagramador com a finalidade de distribuir adequadamente os elementos que compõem uma publicação. 
Com o desenvolvimento das tecnologias digitais, Lopes (2013) argumenta que o termo editoração eletrônica passou a ser utilizado com a introdução de novos softwares para a composição de publicações virtuais. De acordo com Falleiros (2002), a editoração eletrônica é definida como o ramo da computação gráfica voltado para a produção de peças gráficas e editoriais. Para o seu desenvolvimento, são utilizados diversos softwares: processadores de texto (Microsoft Word e Open Office), ferramentas em linguagem de programação (LaTeX), programas de ilustração vetorial (Corel Draw e Adobe Illustrator), programas de edição de imagens (Photoshop), programas paginadores e de diagramação (InDesign, Framemaker e Scribus), entre outros.

Após trazermos alguns conceitos oriundos das artes gráficas e do design gráfico, focamonos em refletir sobre o conceito de editoração: um processo que trata do preparo de um texto original, também denominado de manuscrito, em uma publicação de caráter periódico ou não, por meio de procedimentos editoriais que envolvem uma sequência de fases a depender do produto e da finalidade deste.

Por exemplo, no caso específico da editoração de um livro em uma editora universitária, o original é submetido a um conselho ou comitê editorial, o qual irá avaliar a obra, aprová-la ou recusá-la conforme as políticas editoriais. Se aprovado, o manuscrito passará para a revisão textual e normalização, e ambos os trabalhos são realizados por profissionais específicos. No caso da revisão textual, cabe aos profissionais da área de Letras a responsabilidade pela correção ortográfica e gramatical, um trabalho minucioso e muitas vezes demorado, pois exige concentração e domínio da escrita em língua vernácula por parte de quem o executa. Aos bibliotecários, compete à atividade de normalização bibliográfica, que exige o conhecimento sobre as normas da série informação e documentação da Associação Brasileira de Normas Técnicas (ABNT), no caso de livros publicados no Brasil. Após as revisões e normalização, o original é enviado para a criação do projeto gráfico e, em seguida, para a diagramação da obra (tipografia, espaçamento, capa, imagens etc.), levando em consideração o público a quem se destina.

Durante a execução do projeto gráfico e da leitura de provas em publicações editoriais, há sempre uma permanente revisão gramatical e de normalização. Na finalização, é preciso, ainda, produzir a ficha catalográfica e observar se o sumário, índice e os dados dos autores estão corretos. Os passos seguintes dependem se o livro for publicado em formato impresso ou eletrônico, o que pode gerar dois arquivos diferentes, a depender da escolha do suporte, para a mesma obra. Em todas as etapas, o editor está acompanhando de perto e em contato direto com o autor, aconselhando e chamando atenção a detalhes que apenas esse profissional pode observar, a fim de fazer nascer o livro.

No caso do periódico científico de acesso aberto, isto é, disponível de forma gratuita na internet, o processo de editoração envolve outra dinâmica para publicação, a qual requer a atuação de diversos profissionais, a saber: equipe editorial, basicamente constituída por uma comissão científica, conselho editorial (também conhecido como comitê ou conselho consultivo), assessores científicos (editores de seção ou editores de área) e revisores (consultores ad hoc, pareceristas ou referees), além de uma equipe de produção editorial, responsável pela parte operacional e técnico-administrativa, como, por exemplo, a secretaria editorial, o bibliotecário, o profissional de revisão em língua vernácula e estrangeira, o responsável pelo suporte técnico, entre outros.

Nem todas as revistas conseguem manter uma equipe editorial completa, por não disporem de budget para tal, na maior parte das vezes. Nas instituições públicas brasileiras, os professores se voluntariam como editores científicos e contam com a ajuda de outros colegas, bem como de bibliotecários, servidores técnicoadministrativos e alunos bolsistas da instituição, para conseguirem realizar o trabalho de gerar edições. Há alguns editais de apoio à editoração e publicação de periódicos científicos; contudo, os pré-requisitos para submissão de propostas que constam nos critérios exigidos não contemplam as revistas recém-criadas, o que se configura como contraditório, uma vez que são esses periódicos que mais precisam de incentivo.

Dessa forma, o processo de editoração de periódicos científicos descrito neste artigo pode não corresponder a todas as realidades vivenciadas pelos editores brasileiros. Algumas atividades podem ser realizadas por apenas um profissional em uma dada revista, e já em outra 
há uma equipe responsável para tal, conforme apresentado no exemplo a seguir:

a) equipes editoriais com recursos reduzidos: apenas o editor responsável pela publicação realiza todas as etapas do processo editorial, algumas vezes com o auxílio de bolsistas da graduação ou pósgraduação;

b) equipes editoriais completas: editor, avaliadores, consultores ad hoc, revisores, bibliotecários, suporte técnico, secretária editorial, jornalistas etc.

Nos últimos anos a participação dos bibliotecários no mercado editorial tem se dado pela atuação de bibliotecas universitárias como editoras de trabalhos acadêmicos produzidos em suas instituições. Em alguns casos, a biblioteca trabalha com a imprensa universitária ou publica trabalhos de forma independente. Como exemplo, citamos a iniciativa Library Publishing Coalition, que visa apoiar a publicação científica pela biblioteca e as atividades de comunicações acadêmicas em conjunto com mais de 50 bibliotecas universitárias, além de incentivar fortemente o acesso aberto:

\begin{abstract}
[...] pensar em bibliotecas universitárias como editoras acadêmicas exigem tanto uma perspectiva histórica quanto um senso de futuro. Também requer uma reconsideração dos editores acadêmicos atuais e sua evolução. Nesse sentido, as bibliotecas têm o potencial de se tornar $\circ$ elo crucial para os fluxos de conhecimento na universidade, trabalhando ambos como fizeram há muito tempo - para coletar o conhecimento produzido mundialmente - como estão fazendo cada vez mais - disseminando o conhecimento produzido no campus em todo o mundo. E, de fato, surgiu nos últimos anos uma série de novos modelos de publicação baseados em bibliotecas, incluindo a intensificação das relações entre a biblioteca e as universidades existentes, bem como o estabelecimento de novas editoras dentro das estruturas das bibliotecas. (COHEN; FITZPATRICK, 20I5, p. VII, tradução nossa).
\end{abstract}

Em suma, uma realidade comum no cenário brasileiro é a de que várias instituições são responsáveis pela publicação de periódicos, provendo recursos próprios, financeiros e humanos para gestão e editoração, além de fornecer o espaço físico em suas instalações e infraestrutura tecnológica para efetivar a publicação da revista e compor uma equipe editorial. Deveras, muitos desses editores brasileiros são docentes e pesquisadores renomados, com produção acadêmica relevante para a sua área, os quais assumem a missão de ser editor e levar adiante a luta diária pela manutenção da publicação.

\section{MERCADO EDITORIAL: áreas de atuação e atividades possíveis}

Constatamos a presença do bibliotecário no mercado editorial, primordialmente, em periódicos científicos e em editoras comerciais e universitárias. Com base em experiências vivenciadas no mercado de trabalho e em atividades extraclasse realizadas com alunos da disciplina Editoração, ministrada no curso de Biblioteconomia, verificamos que ainda são poucos os bibliotecários que atuam nessa área. Isso pode ocorrer devido à falta de conhecimento por parte do mercado editorial das diversas competências que esse profissional desenvolve durante a graduação, as quais podem ser um diferencial para uma empresa/ instituição editorial. Destarte, compreendemos como fundamental a participação das entidades de classe dos bibliotecários na divulgação das diversas competências e áreas de atuação, ampliando, assim, as possibilidades e os nichos mercadológicos. A seguir, apresentamos algumas das atividades que o bibliotecário pode desenvolver fazendo parte de equipes editoriais de periódicos científicos.

Inicialmente, na análise de provas editoriais, o bibliotecário participa do fluxo e da gestão do processo editorial, analisando a versão pré e pós-publicação dos artigos, além de ser o responsável por encaminhar o documento para uma nova revisão gramatical ou para acertos necessários antes da publicação da versão definitiva de um artigo ou da composição final da revista (versão completa e na íntegra do volume e número). A leitura de prova também é apresentada ao editor, a fim de que este avalie, tome conhecimento e dê ciência da versão final apresentada. 
Outra função elencada é a assessoria aos editores, autores e pareceristas. Esta é mais ligada à figura da secretária editorial, a qual possui a missão de assessorar o editor no desempenho de suas funções e garante a operacionalidade da revista, ou seja, assessoria e acompanhamento de todo o fluxo editorial. Além disso, auxilia autores e pareceristas dentro do sistema de submissão dos artigos, em casos como problemas de acesso e senha, acompanhamento e situação da submissão, atuando como mediador entre autores, avaliadores, editores e profissionais de suporte técnico e tecnologia da informação na resolução de problemas.

A consultoria e avaliação técnica de revista para inclusão em bases de dados são áreas conquistadas gradativamente pelo bibliotecário dentro das equipes editoriais, afinal, a responsabilidade de buscar, incluir, enviar e acompanhar a submissão de um periódico científico em bases de dados, diretórios, portais e repositórios era atribuição exclusiva do editor da revista, responsável por executar essa tarefa ou delegá-la. Contudo, a evolução da tecnologia e a inserção do bibliotecário dentro das equipes editoriais mostraram que esse profissional é capacitado para a função e, por consequência, passou a ser a figura responsável pela tarefa. Além disso, o bibliotecário possui competências necessárias para indexar o conteúdo da revista por ter habilidades para garimpar toda e qualquer fonte de informação. Esse processo de indexação em bases de dados e diretórios promove visibilidade e qualidade para a revista científica.

A catalogação na fonte (produção da ficha catalográfica) já é uma tarefa tradicionalmente exercida pelo bibliotecário, executada também em periódicos científicos, voltada para a inclusão da ficha catalográfica na composição final do periódico ou inserção da ficha no verso da folha de rosto em periódicos impressos, ou até mesmo a exibição da catalogação na fonte em alguma seção de créditos ou informações sobre a revista, no caso de periódicos eletrônicos.

Sobre a conferência da terminologia e indexação, isto é, a atribuição das palavraschave e dos descritores utilizados em um periódico científico, é importante ressaltar que essa atividade é imprescindível, pois assevera a qualidade dos metadados, com os quais estão intrinsecamente ligados, além de assegurar uma melhor recuperação da informação da revista nos buscadores, em bases de dados, diretórios, portais e indexadores. Se até mesmo na antiguidade o filósofo Sócrates reconhece que "o princípio da sabedoria é a definição dos termos", apreende-se que "[...] devemos adotar esta sabedoria por padronização e abraçar estas definições" (GILLETTE, 2017, online). Nesse sentido, o bibliotecário mantém contato direto, enquanto prática e campo do saber inerente à sua formação, com as taxonomias e ontologias, dentre outros campos relacionados à definição de termos e indexação. Algumas áreas desenvolvem e utilizam vocabulário controlado próprio, como, por exemplo, a maioria das revistas da área de saúde, que recorre aos 'Descritores em Ciências da Saúde' (DeCS). Há revistas que possuem um vocabulário controlado ou tesauro exclusivo para o seu periódico científico.

Conforme Rubi (2009, p. 81) a tarefa da indexação "[...] diz respeito à identificação do conteúdo do documento por meio do processo de análise de assunto e à representação desse conteúdo por meio de conceitos". De acordo com a autora, os conceitos são traduzidos e representados em linguagem documentária e serão recuperados em índices, catálogos ou bases de dados; portanto, advém daí a importância de realizar a indexação de forma diligente a fim de se obter uma recuperação da informação mais eficaz.

No que diz respeito aos critérios mais básicos para indexação em bases de dados, os mais cobrados são: a qualidade científica do periódico; a revisão por pares; a transparência nos critérios de avaliação pelos pares e em todo o processo editorial; a representatividade do corpo editorial; a qualidade e o mérito científico dos artigos publicados; o conteúdo dos artigos (priorizando pesquisas e artigos originais); o cumprimento da periodicidade; a normalização; os idiomas de publicação (idioma nativo e outras línguas como fator de internacionalização e visibilidade); e evitar a endogenia - tendência à concentração institucional ou geográfica em um periódico segundo os critérios de avaliação da SciELO Brasil (2014).

A manutenção do site de revistas e a gestão de portais de periódicos não são atribuições exclusivas do bibliotecário. Há profissionais da área de tecnologia da informação (TI) especializados para esse tipo de atividade; 
no entanto, o bibliotecário pode exercer essa função com desenvoltura, de acordo com o seu conhecimento técnico e específico aplicado à área de TI. Em relação aos bibliotecários que possuem um conhecimento técnico mais aprofundado, não podemos deixar de citar os aspectos relacionados à navegação nos sites e portais de periódicos e de elementos básicos da arquitetura da informação, afinal, estes são essenciais na garantia de acesso e êxito de qualquer periódico eletrônico. Sobre isso, a literatura científica cita o estudo Eye tracking da Universidade de Stanford e do Poynter Institute. Esse estudo empírico, centrado em arquitetura da informação e user eXperience (UX) serve para medir a usabilidade e monitorar o comportamento dos usuários ao lerem páginas da Web. O sistema usado rastreia o caminho percorrido pelo olhar humano durante a leitura em diferentes ambientes digitais e analógicos (FRANCO, 2008; VIDOTTI et al., 2016).

Para os bibliotecários, ter conhecimento em programação ou conhecimentos mais específicos da área de TI não é mandatório, pois não faz parte de seu métier, todavia, ainda assim é fundamental que o bibliotecário possa dialogar com os profissionais da área de TI nas seguintes situações:

a) bibliotecários sem o conhecimento aprofundado em TI: situações simples relacionadas a problemas técnicos, tais como problemas de acesso (não conseguir efetuar login na plataforma da revista), falha no upload de documentos, alterações em layout e aparência do periódico, entre muitas outras situações pontuais que são reportadas ao bibliotecário pela equipe editorial, por autores e avaliadores. Então, cada um desses problemas é previamente avaliado pelo bibliotecário e, na sequência, repassado para a equipe de $\mathrm{TI} /$ profissional responsável para o devido ajuste, mitigação e resolução de problemas, ou seja, o bibliotecário repassa as demandas para o profissional especializado;

b) bibliotecários que possuem o conhecimento técnico, especializado e aprofundado em TI: apesar de ainda não ser obrigatório o conhecimento em programação, manutenção e criação de sites e portais, este tem sido um enorme diferencial para a atuação do bibliotecário, afinal, ele não apenas conversa e realiza uma espécie de mediação de conflitos entre a equipe editorial e os responsáveis pela área de TI, mas também participa, intervém, colabora e, muitas vezes, resolve sozinho ou juntamente com a equipe de TI os problemas relacionados à programação, manutenção de sites, criação e gestão de portais, alteração em folhas de estilo CSS (Cascading Style Sheets) para ajuste de layout em periódicos científicos eletrônicos, dentre outras atribuições.

Outra atividade tradicional para o bibliotecário no campo dos periódicos é a expedição e distribuição da revista por meio do controle de assinaturas, permuta e doação. O controle de assinaturas é acompanhado, geralmente, pelo bibliotecário que atua na revista assinada, assim como pelo bibliotecário da instituição assinante de um periódico científico. Diversas bibliotecas ainda mantêm suas coleções físicas de periódicos impressos, e uma forma de manter a coleção corrente e obter fascículos é a permuta com outras instituições, em troca de outros títulos ou duplicatas, além de receber doações de revistas de diversas organizações.

Apesar de existirem profissionais específicos para trabalhar com a diagramação, há bibliotecários exercendo a função de diagramador em periódicos científicos. Nesse sentido, o trabalho do bibliotecário diagramador é ordenar os elementos, uniformizar gráfica e editorialmente, aplicando uma padronização que aliará toda a estrutura a ser apresentada para o leitor, sem deixar de lado a filosofia do periódico, a imagem que este deseja passar e, sobretudo, apresentar a revista como um veículo eficaz de comunicação científica. Basicamente, o bibliotecário atuante neste segmento preocupa-se com os elementos gráficos que serão utilizados, tais como: cores, a relação entre as ideias apresentadas e os elementos gráficos, a ordem de apresentação, frases e períodos, agrupamento das letras, recursos tipográficos, vinhetas, ilustrações, zonas brancas nas páginas, as zonas de visualização da página (impressa ou digital), em suma, todo este ofício se traduz em um bom senso estético que deve primar pela legibilidade.

A atividade de divulgação de periódicos científicos requer diversas estratégias aplicadas por editores, bibliotecários e equipes editoriais, definindo, inclusive, equipes multidisciplinares que contam com jornalistas para executar essa tarefa. Contudo, editores e bibliotecários também têm trabalhado com a divulgação das revistas científicas em mídias sociais e em diversos canais de comunicação. 
Muitas revistas criaram fan pages no Facebook, perfil no Google Acadêmico, Twitter, redes sociais acadêmicas (tais como Academia.edu, ResearchGate, Mendeley etc.), visando divulgar o periódico científico.

O uso de mídias sociais na divulgação científica demonstra como todos os profissionais envolvidos podem aproveitar o potencial das redes sociais para a comunicação com um público mais amplo, pois estas contribuem para o aumento da visibilidade dos periódicos científicos, influenciam os dados estatísticos e as métricas alternativas (Altmetrics), ampliam a colaboração entre os pesquisadores e aprimoram a comunicação das revistas e instituições, tornando-se um instrumento de diálogo com a sociedade. Diversos pesquisadores, por exemplo, divulgam e compartilham artigos no Twitter, talvez, por isso, muitas revistas passaram a ter perfis nessa rede social.

Para garantir o sucesso na criação e manutenção do tempo de vida de uma revista científica, algumas instituições sensibilizaram-se para a importância do planejamento, idealização e construção de um periódico científico. Assim, é comum que solicitem a consultoria ou o auxílio de um bibliotecário para elaborar projetos de criação ou de outra natureza relacionados a esse universo. Portanto, a elaboração de projetos é mais uma função atribuída ao bibliotecário, afinal, é o profissional competente para essa tarefa.

Além da elaboração de projetos, o bibliotecário tornou-se também a figura responsável por elaborar diferentes relatórios relacionados aos periódicos, desde relatórios financeiros e de prestação de contas até os relatórios de acessos, downloads, visualizações, taxa de rejeição de artigos, entre outras variáveis. Contudo, para obter dados tão fidedignos na elaboração desses relatórios, o bibliotecário precisa ser organizado, no sentido de coletar e armazenar essas informações, pois nem sempre é possível contar com sistemas robustos que armazenem os dados e todas essas informações relacionadas ao fluxo editorial, sistemas que possuam funções e opções variadas de relatórios que possam ser recuperados a fim de comparar o desempenho da revista. Como exemplo, citamos alguns relatórios existentes em plataformas Open Journal Systems (OJS), como os relatórios de estatísticas de edições publicadas, de artigos publicados, submetidos, rejeitados, aceitos etc. Entretanto, exatamente por questões técnicas relacionadas ao sistema, nem sempre estes relatórios são fidedignos e refletem a realidade, por exemplo: em plataformas OJS, artigos que entram no sistema através do plugin de submissão rápida, que permite enviar documentos publicados diretamente em determinada edição, sem passar por todas as etapas típicas de avaliação por pares e de edição do documento, apresentarão divergências entre os dados e as estatísticas de artigos aceitos e rejeitados, uma vez que estes não passaram pelo processo e fluxo tradicional até serem publicados. $\mathrm{O}$ próprio sistema OJS alerta que os percentuais podem não somar $100 \%$, afinal, itens submetidos novamente podem ser aceitos, rejeitados ou estarem em processo de avaliação, e itens submetidos via plugin de submissão rápida também afetarão estes números. Esse plugin é usado em diversas situações, inclusive em casos de revistas que publicavam apenas números impressos e passaram a publicar fascículos eletrônicos e, assim, trazem os números impressos para a plataforma digital.

Já quanto aos relatórios de acessos, downloads e visualizações, o bibliotecário pode contar com o auxílio das técnicas de Search Engine Optimization (SEO) ou de ferramentas de análise de tráfego, como o AddThis, recurso este existente no OJS com um indicativo para realizar inscrição e criar uma conta, além de outras configurações necessárias no servidor da revista em algumas situações. Portanto, mais uma tarefa que o bibliotecário pode realizar sozinho ou contar com o apoio da equipe especializada em TI.

O serviço de formatação dos manuscritos e a normalização são tarefas atribuídas ao bibliotecário, uma vez que é o profissional capacitado para a elaboração e auxílio em processos de padronização. A ciência exige padrões; portanto, estabelecer critérios e diretrizes de normalização em periódicos científicos é imperativo para determinar e garantir sua qualidade.

\footnotetext{
As padronizações existem para nos auxiliar. As normas facilitam a comunicação, mas não são simplesmente setas para indicar o caminho a seguir, embora algumas tenham a conotação de sentido obrigatório. Aliado ao conhecimento de padronizações, normas
} 
e suas atualizações, o discernimento e a sensibilidade humana são essenciais para a produção de um bom texto. (PEREIRA, 20II, p. 2II)

Entretanto, apesar de a aplicação das normas serem importantes para os periódicos científicos, o bom senso deve prevalecer, e o estabelecimento de alguns padrões próprios não é proibido, desde que não firam as normas:

\begin{abstract}
O projeto gráfico é de responsabilidade do editor e/ou editora da publicação, respeitando-se o formato, layout e tipologia gráfica, além de recomendar que qualquer mudança gráfica na revista seja realizada apenas se for necessário e que ocorra no início de um novo volume. (ASSOCIAÇÃO BRASILEIRA DE NORMAS TÉCNICAS, 20I5, p. 8).
\end{abstract}

A supervisão de marcação em eXtensible Markup Language (XML) é uma função executada por bibliotecários que compreendem a referida linguagem, ou por profissionais da área de TI. A construção bem elaborada da XML garante a qualidade dos metadados, da apresentação em diversos formatos dos artigos, entre muitas outras aplicações possíveis com a XML. A XML é uma linguagem de marcação recomendada pela World Wide Web Consortium (W3C) para a criação de documentos com dados organizados hierarquicamente, tais como textos, banco de dados ou desenhos vetoriais. A linguagem XML é classificada como extensível porque permite definir os elementos de marcação, e uma das vantagens de sua utilização é a interoperabilidade. Por seu potencial, descreve a estrutura e o significado dos dados, ou seja, separa a estrutura e a exibição dos dados, além de possibilitar a criação de tags (etiquetas) sem limitação. Outra aplicação que utiliza essa linguagem em periódicos científicos eletrônicos é a atribuição do Digital Object Identifier (DOI) para os artigos. Trata-se de identificador digital para entidades digitais e conjuntos de dados e seu uso permite a implementação de serviços associados aos metadados depositados junto ao identificador (BRITO et al., 2015).

Em relação à preservação digital, os bibliotecários trabalham junto à equipe de TI para estabelecer os mecanismos necessários visando garantir a preservação de seus conteúdos. O bibliotecário também contribui para a preservação digital de revistas científicas ao escolher como um dos formatos disponibilizados o PDF/A, pois este é o padrão apropriado que fornece especificações para criação, visualização e impressão de documentos digitais usados para preservação em longo prazo (ADOBE ACROBAT, [200-]).

Para preservar os conteúdos digitais de periódicos científicos, também é papel do bibliotecário elaborar uma política de preservação digital, ou adotar a existente institucionalmente, além de ser obrigatório o conhecimento básico em estratégias de preservação, como, por exemplo: migração, digitalização, replicação, preservação de tecnologias existentes, estabelecimento de padrões mínimos de interoperabilidade, emulação, dentre outros aspectos. É essencial, ainda, conhecer as iniciativas de preservação digital, tais como: Rede Cariniana, LOCKSS, CLOCKSS, Archaeology Data Service, British Library, E-Depot, HathiTrust, Pandora, Portico, PKP Preservation Network, Library of Congress, Scholars Portal, Swiss National Library, entre outras. Evidentemente, esse trabalho não pode envolver apenas um bibliotecário, mas sim uma equipe especializada para realizá-lo no intuito de manter as coleções de periódicos científicos eletrônicos.

Além de todas as ações supracitadas que o bibliotecário pode desenvolver no ramo da preservação digital, há outras atividades relacionadas, como a curadoria, que vem crescendo e acompanhando as tendências internacionais. Desse cenário, emerge o 'bibliotecário de dados', definido por Sales e Sayão (2017, p. 142) como o "Profissional da área de biblioteconomia com formação em gestão de repositórios de dados e de curadoria, indexação e catalogação de dados e conhecedor dos fluxos das pesquisas locais". Pode parecer incomum tratar desse assunto voltado ao universo dos periódicos científicos, contudo, há revistas que encorajam o compartilhamento de dados brutos oriundos da pesquisa que embasou o artigo publicado, inclusive, possuem práticas voltadas para a gestão de dados. Exemplos de periódicos científicos que adotam e/ou incentivam esses modelos são: Information Science, Nature, Science, Library \& Information Science Research, Informação em Pauta, entre muitas outras.

$\mathrm{Na}$ tentativa de ilustrarmos, da melhor forma, o ofício do bibliotecário em editoração, apresentamos, a seguir, no Infográfico 1 construído com base em Santana e Francelin (2016): 
Infográfico 1: Atividades dos bibliotecários em equipes editoriais.

Secretaria Editorial (Participação em todo o fluxo editorial, assessoria a autores e pareceristas, gestāo do processo editorial etc.)

Gestấo de processos (da pré-avaliação à publicaçăo)

Assessoria aos autores

e pareceristas

\section{Consultoria}

Avaliaçâo técnica de revista para inclusăo em bases de dados

Indexação e conferência da terminologia (descritores, palavraschave e vocabulários controlados)

\section{Catalogaçăo na fonte}

Divulgaçăo

Supervisão/narcação en extensible Markup Language (XML)

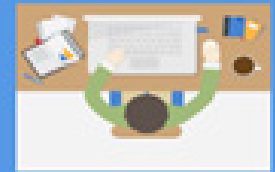

Normalizaçâo (formataçâo dos manuscritos, revisăo

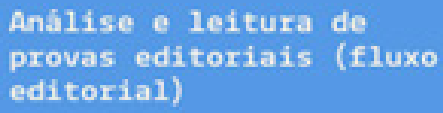
provas editoriais (fluxo editorial)
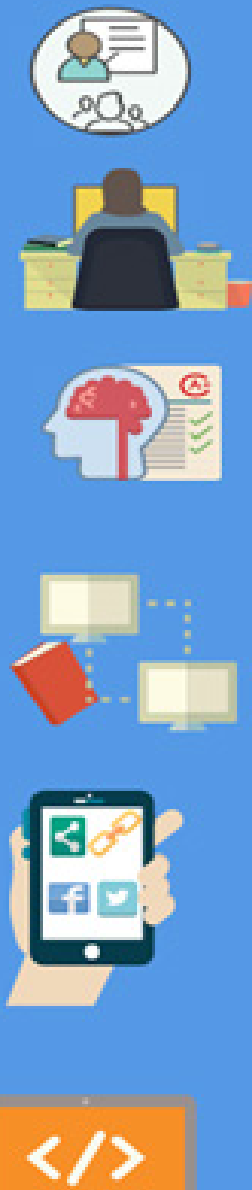
técnica, criação e avaliaçäo de normas e diretrizes para a publicaçăo periódica, solicitação do ISSN, etc.)

Elaboração de projetos

Diagramação com a utilizaçấo de diversos softwares

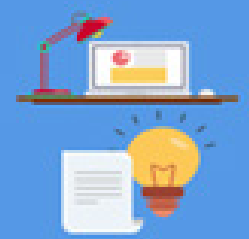

Manutenção do site da revista

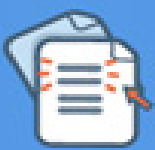

Elaboraçâo de relatórios

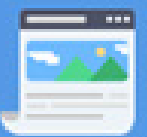

Prestação de contas

Expedição e distribuição (controle de assinaturas, permuta, doaçào e distribuiçāo)

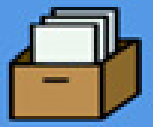

Preservação digital
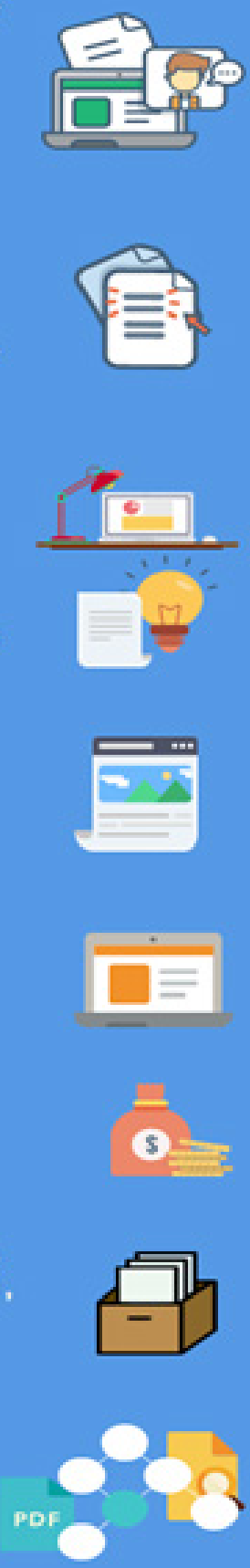

Atribuição de Digital Object Identifier (DOI)

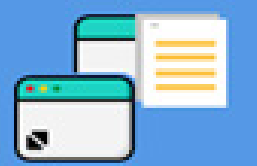

Fonte: Elaborado pelos autores, baseado em Santana e Francelin (2016). 
Diante do exposto, é notória a inserção do bibliotecário em diversas áreas relacionadas à editoração; portanto, o nicho mercadológico possibilita a atuação desse profissional no processo de planejamento, construção e manutenção de vários tipos de produtos editoriais. Assim, definir e mapear as competências desse profissional é imprescindível no sentido de aliar conhecimentos, habilidades e atitudes ao cotidiano dos ambientes de editoração.

\section{COMPETÊNCIAS DO BIBLIOTECÁRIO PARA ATUAR NA EDITORAÇÃO}

Ao refletirmos sobre competência, compreendemos que esse termo está diretamente relacionado à capacidade de agir de forma eficaz em diferentes situações, ou seja, é a junção de conhecimentos, habilidades e atitudes. Conforme Perrenoud (1999), ser competente significa colocar em ação e em sinergia vários recursos cognitivos complementares, entre os quais estão os conhecimentos e as representações da realidade, que construímos e armazenamos a partir de nossa experiência e de nossa formação, mobilizando, assim, conhecimentos para enfrentar um conjunto de situações complexas, implicando também uma capacitação de atualização dos saberes.

Percebemos que o nicho de mercado para o bibliotecário em editoração é bastante promissor, e a sua atuação se torna necessária por meio de competências técnicas e comportamentais. Como exemplo, há competências que giram em torno do conhecimento das plataformas digitais destinadas à gestão de periódicos científicos, tais como o Open Journal Systems (OJS), Ambra, Scholastica, Scholar One, entre outros sistemas, pois nem sempre os editores das revistas conseguirão gerenciar sozinhos toda a cadeia de publicação de um artigo e, por isso, necessitam do apoio de uma secretaria editorial e de uma equipe multidisciplinar para auxiliar nos processos editoriais.

O bibliotecário que atua em equipes editoriais de periódicos científicos trabalha, de certa maneira, com a gestão do conhecimento. Relacionados às revistas científicas, para Stefano (2014, p. 16), "Os setores de produção, serviços e informações se fundamentam no conhecimento, e as organizações de negócios evoluíram [...]. Assim, o conhecimento, um ativo intangível, constitui-se, agora, no recurso econômico mais importante para as organizações". Nesse sentido, cabe pensar em estratégias de colaboração, marketing profissional e, em alguns casos, de capacitação/treinamento com os professores das universidades, programas de pós-graduação, ou mesmo de graduação, que se interessarem em implantar ou que já tiverem uma revista eletrônica disponível na internet, levando em consideração todo o fluxo editorial da revista. Para Leme (2005), são necessárias ao bibliotecário competências técnicas e comportamentais (Infográfico 2), as quais condicionam a sua atuação nos vários papéis que esse profissional pode desempenhar. 
Infográfico 2: Competências do bibliotecário para atuar na editoração

\section{Competências técnicas}

- Conhecimento do fluxo editorial;

- Conhecer indexadores, diretórios e bases de dados;

- Correlacionar a linguagem do autor com os vocabulários controlados existentes;

- Comunicação verbal e escrita;

- Oratória;

- Aptidão para realizar pesquisas aprofundadas na internet;

- Capacidade de análise e síntese;

- Aptidão para desenhos, pinturas e definição de layout;

- Conhecimento em softwares de design e artes gráficas;

-Domínio de normalização, ferramentas para gerenciamento de referências e padronizações em publicações

editoriais;

- Conhecimento e domínio em editores de texto;

- Conhecer e dominar língua vernácula;

-Conhecimento em outras línguas estrangeiras;

- Afinidade com as regras ortográficas e gramaticais da língua portuguesa;

- Conhecer as principais mudanças trazidas pelo acordo ortográfico;

- Saber usar e recomendar o uso dos marcadores de discurso ao longo do texto;

-Dominar interpretação textual;

-Aptidão para gerenciar processos.

\section{Competências comportamentais}

- Alteridade

-Assertividade;

-Atenção;

-Atualização contínua;

-Autonomia;

- Concentração;

- Cordialidade;

- Criatividade;

- Curiosidade;

-Diligência;

-Dinamismo;

-Eloquência;

-Ética

- Imparcialidade;

-Inteligência emocional;

-Liderança;

-Motivação;

- Organização;

-Proatividade;

-Relacionamento Interpessoal;

-Resiliência;

-Senso estético;

-Visão holística.

Fonte: Elaborado pelos autores (2018). 
Dentre as competências comportamentais, ser proativo certamente possibilitará o mapeamento da realidade das publicações no contexto universitário, identificando aspectos como a periodicidade das revistas, quem são os responsáveis pela gestão do periódico e o que se pretende alcançar, de fato, com o status que o título poderá adquirir no futuro. O bibliotecário precisa ter a visão do todo para que possa agir exatamente na função que lhe compete no processo editorial. Portanto, a proatividade fará com que as oportunidades sejam enxergadas numa perspectiva de gestão da informação.

Desse modo, mapear as publicações exige do bibliotecário a atitude de entrar em contato com os editores gerentes dos periódicos científicos, tendo em mente que pode ocorrer, inclusive, de alguns deles desconhecerem determinados indexadores, bases de dados e diretórios especializados, cujos critérios de aceitação do título perpassam pela mediação do bibliotecário. Além disso, planejar e participar de reuniões com os editores, quando e se necessário, favorece a definição de metas a serem alcançadas pelas revistas, metas essas atreladas à consolidação do periódico em sua área específica do conhecimento. Assim, as habilidades para lidar com pessoas devem ser desenvolvidas no seio das competências comportamentais, uma vez que cada editor e cada membro do corpo editorial terá um perfil próprio, com o qual o bibliotecário precisará lidar nessa empreitada.

Diante dos entraves que podem surgir nessa tentativa do bibliotecário se inserir no processo editorial, entendemos que a liderança e a capacidade de negociação se tornam aliadas para que se alcancem os objetivos. As parcerias de trabalho nem sempre são construídas a partir do bibliotecário, algo compreensível se levarmos em consideração a necessidade de sensibilizar a comunidade de editores acerca da importância do serviço prestado por esse profissional. O que estreitaria as relações é justamente a realização de um mapeamento técnico da situação das revistas científicas na universidade, centro universitário ou faculdade onde se atua. Esse mapeamento exige competências técnicas inerentes à formação do bibliotecário, como planejamento, seleção, tratamento e disseminação da informação. A partir destas reflexões, propomos um esquema (Figura 1) baseado em alguns serviços de informação básicos e na tríade que compõe a competência: conhecimentos, habilidades e atitudes ( $\mathrm{CHA})$ que o bibliotecário deve ter para atuar no campo da editoração. 
Figura 1: Conhecimentos, habilidades e atitudes para o bibliotecário atuar na editoração

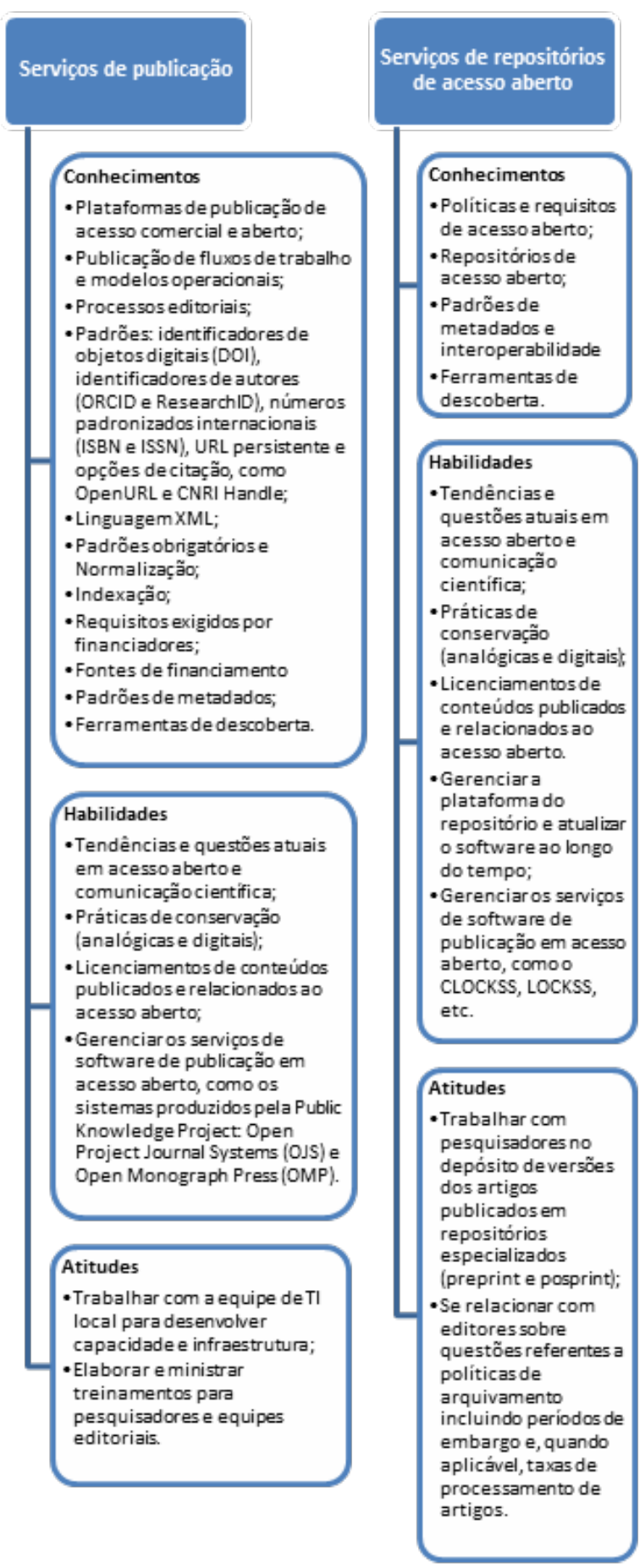

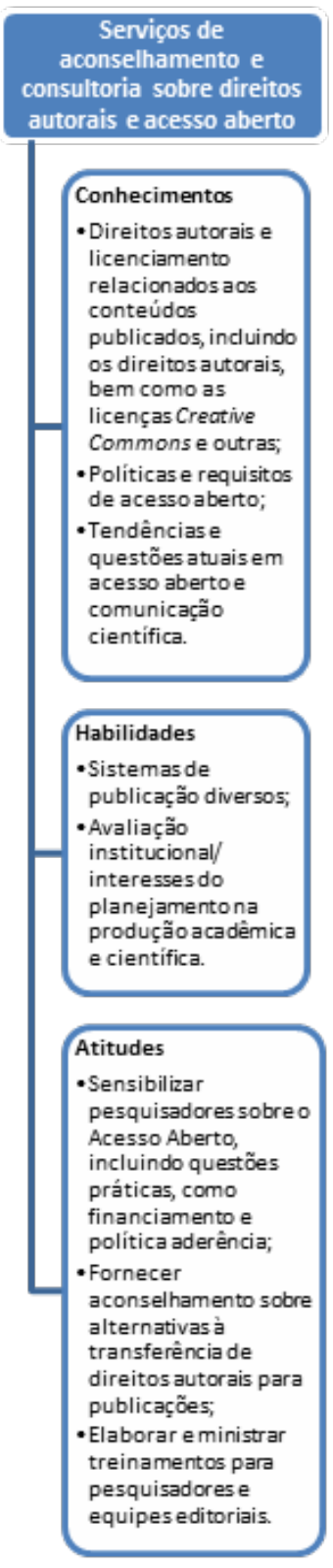

Avaliação de recursos agregadores de valor

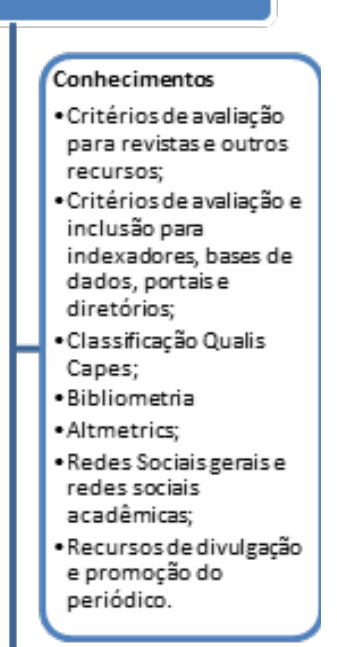

Habilidades

- Políticase

procedimentos de promoçãoe posse de professores;

- Avaliação

institucional/interesses do planejamento na produçãoacadêmica e científica.

\section{Atitudes}

- Fornecer apoio ao pesquisador, autor, instituição de ensino superior na avaliação de revistas e outros recursos acadêmicos; - Fornecer

aconselhamento institucional aos departamentos dos cursos, pesquisadorese ao setor de aquisição de bibliotecas em indicadores de qualidade.

Fonte: Elaborado pelos autores, adaptado de Calarco et al. (2016). 
Para atuar no campo da editoração, vimos que é primordial ao bibliotecário desenvolver e trabalhar competências técnicas e comportamentais inerentes ao mercado editorial. Além das editoras de caráter comercial, independente ou universitário, a atuação do bibliotecário é imprescindível na composição de equipes de periódicos científicos, onde conhecimentos, habilidades e atitudes afloram desde as experiências em estágios ou bolsas na graduação até à efetiva gestão da informação e do fluxo editorial.

Dependendo de sua afinidade e, obviamente, da necessidade das revistas científicas, o bibliotecário pode atuar na secretaria editorial, revisão e edição de texto, normalização, diagramação, indexação e em treinamentos. Para cada uma dessas atribuições há competências específicas, e o desafio se torna maior diante das mudanças tecnológicas e normativas, que condicionam a publicação de periódicos eletrônicos. Como exemplo, temos a classificação Qualis Capes, definida como um sistema de classificação de periódicos em cada área do conhecimento desenvolvido e coordenado pela Coordenação de Aperfeiçoamento de Pessoal de Nível Superior (Capes). A classificação dos cursos de pós-graduação tem como um dos principais componentes a avaliação dos periódicos onde são publicados os resultados das pesquisas. Por sua vez, a posição dos periódicos no ranking determina seu prestígio e influencia a quantidade e qualidade dos trabalhos submetidos. A classificação de periódicos é realizada pelas áreas de avaliação e passa por processo anual de atualização. Esses veículos são enquadrados em estratos indicativos da qualidade, a saber: A1 (mais elevado); A2; B1; B2; B3; B4; B5; C.

O conhecimento gerencial acerca do fluxo editorial da revista deve ser complementado com o conhecimento técnico sobre as fontes de informação para indexação em repositórios, bases de dados e diretórios que elevem o patamar do periódico científico. Da mesma forma, as habilidades e atitudes necessárias para o desempenho dessas atividades devem ser trabalhadas constantemente, pois o nível de exigência do mercado aumenta dia após dia, diretamente proporcional à concorrência nesse mercado. Por isso, a postura proativa do bibliotecário certamente o fará um profissional valorizado entre os demais profissionais da equipe editorial, na qual todos trabalham em sinergia em prol do alcance de resultados e de metas cumpridas.

\section{CONSIDERAÇÕES FINAIS}

Concluímos que a editoração se configura como um processo que perpassa desde a produção intelectual do preparo de um manuscrito (texto original) até a publicação da obra, impressa ou digital, por meio de procedimentos editoriais, envolvendo fases sequenciais a depender do produto e da finalidade deste. Talvez possamos refletir que o conceito de editoração, diretamente ligado ao de editor, pode ser ampliado para até mesmo a chegada da obra às mãos dos leitores e o feedback que estes fornecem aos autores/editores, uma vez que há editoras que trabalham com foco em conquistar clientes por meio das próprias opiniões destes, analisando seus perfis e possíveis nichos mercadológicos para inserção de novos gêneros literários.

Desse modo, ressaltamos as inúmeras possibilidades de atuação do bibliotecário na editoração para além dos ambientes tradicionais, como, por exemplo, em editoras, livrarias, portais de periódicos, revistas científicas, repositórios institucionais, agências de publicidade, como consultores de direitos autorais, preservação digital, indexação, catalogação na fonte, vocabulários controlados, indexadores, diretórios e bases de dados. O bibliotecário desenvolve ainda durante sua formação, a depender obviamente do seu interesse em determinadas áreas, competências técnicas para atuar com softwares de design e artes gráficas, manutenção do site de revistas, diagramação com a utilização de diversos softwares, análise e leitura de provas editoriais, elaboração de projetos e relatórios, supervisão de marcação em XML, criação e atribuição de identificadores digitais (DOI) e secretaria editorial, com o assessoramento direto ao editor, participação em todo o fluxo editorial, assessoria a autores e pareceristas, gestão do processo editorial desde a pré-avaliação até a publicação, capacitação de editores e de toda a equipe editorial.

Enfatizamos a necessidade dos profissionais se preocuparem em não apenas 
desenvolver competências técnicas específicas para cada tipo de serviço de informação a ser executado, pois as teorias da gestão por competência têm nos mostrado a premência em refletir e disseminar a relevância do desenvolvimento consciente da competência comportamental. O bibliotecário precisa levar para o mercado de trabalho o diferencial, unindo competências técnicas, como as citadas acima, com as comportamentais, dentre as quais ratificamos: autonomia, concentração, cordialidade, criatividade, curiosidade, diligência, dinamismo, eloquência, inteligência emocional, liderança, motivação, organização, proatividade, relacionamento interpessoal, resiliência, senso estético e visão holística. Cabe a cada profissional procurar especializar-se na área de atuação desejada.

\section{Artigo recebido em I I/03/20I8 e aceito para publicação em 15/04/20I8}

\section{LIBRARIAN AND EDITING: niche market and needed skills}

ABSTRACT The work impressions experienced in the teaching profession, in the experience of conducting an electronic scientific periodical and in the librarian practice obtained through the editorial process on Open Journal System (OJS), also based on a literature review, allow the production of this communication with the objective of present the areas of activity of the librarian in the world of publishing and the technical and behavioral skills required to do so. The presence of the librarian in the publishing market has been perceived mainly in scientific journals and in commercial and university publishing houses, but in a very modest way, few librarians work in publishing, which can occur due to the lack of knowledge on the part of the editorial market of the diverse skills that this professional develops during the graduation, which can be a differential for a company/publishing institution. This professional can act in the analysis of editorial tests, in the advising to the editors, authors and referees, in the consulting and technical evaluation of magazine for inclusion in databases, cataloging in the source, conference of the terminology and indexation, elaboration of different reports related to the journals, as well as many other areas. For this, it must develop technical skills, such as: knowledge of the editorial flow, of indexers, directories and databases; to correlate the author's language with existing controlled vocabularies; be capable of analysis and synthesis; to know design software and graphic arts; have mastery of standardization, reference management tools and standardization in editorial publications among many others; in addition to behavioral skills, such as: assertiveness; autonomy; concentration; creativity; diligence; dynamism; impartiality; emotional intelligence; leadership; motivation; organization; proactivity; interpersonal relationship and aesthetic sense.

Keywords: $\quad$ Publishing. Librarian. Areas of expertise. Technical and behavioral skills.

\section{REFERÊNCIAS}

ADOBE ACROBAT. Configurações de conversão do Adobe PDF. [200-]. Disponível em: <https:// helpx.adobe.com/pt/acrobat/using/pdfconversion-settings.html\#about_pdf_x_pdf_e_ and_pdf_a_standards>. Acesso em: 07 abr. 2018.

ARAÚJO, E. A construção do livro: princípios da técnica de editoração. Rio de Janeiro: Nova Fronteira; Brasília: INL - Instituto Nacional do Livro, 1986.
ASSOCIAÇÃO BRASILEIRA DE NORMAS TÉCNICAS. NBR 6021: Publicação periódica técnica e/ou científica. Rio de Janeiro, 2015.

ASSOCIAÇÃO DOS DESIGNERS GRÁFICOS. ABC da ADG: glossário de termos e verbetes utilizados em Design Gráfico. São Paulo: Melhoramentos, 2000.

BAER, L. Produção gráfica. São Paulo: Senac, 1999.

BRAGANÇA, A. Sobre o editor. Notas para sua história. Em Questão, Porto Alegre, v. 11, n. 2, p. 
219-237, jul./dez. 2005. Disponível em: <http:// seer.ufrgs.br/index.php/EmQuestao/article/ view/119>. Acesso em: 13 set. 2017.

BRITO, R. F. de et al. Guia do usuário do Digital Object Identifier. Brasília: Instituto Brasileiro de Informação em Ciência e Tecnologia, 2016. Disponível em: <https://www.abecbrasil.org. br/arquivos/Guia_usuario_DOI-online3.pdf>. Acesso em: 07 abr. 2018.

CALARCO, P. et al. Librarians' Competencies Profile for Scholarly Communication and Open Access. 2016. Disponível em: <https://www. coar-repositories.org/files/Competencies-forScholComm-and-OA_June-2016.pdf>. Acesso em: 20 jul. 2017.

CAMPOS, V. C. Editoração científico eletrônica: como produzir um periódico científico eletrônico. São Paulo: Dialógica, 2016.

CHARTIER, R. A aventura do livro: do leitor ao navegador. Tradução: Reginaldo de Moraes. São Paulo: Editora Unesp, 1999.

COHEN, D.; FITZPATRICK, K. Foreword. In: BONN, Maria; FURLOUGH, Mike (Ed.). Getting the word out: academic libraries as scholarly publishers. Chicago, Illinois: Association of College and Research Libraries, 2015. Disponível em: <https://www.coar-repositories.org/files/ Competencies-for-ScholComm-and-OA_June2016.pdf>. Acesso em: 20 maio 2017.

COLLARO, A. Projeto Gráfico: teoria e prática da diagramação. São Paulo: Summus, 2000.

CUNHA, A. G. Dicionário etimológico Nova Fronteira da Língua Portuguesa. Rio de Janeiro: Nova Fronteira, 1982.

DIAGRAMAÇÃO. In: FERREIRA, A. B. de H. Aurélio online. 2017. Disponível em: <https:// dicionariodoaurelio.com/diagramar $>$. Acesso em: 20 maio 2017.

FALLEIROS, D. O Mundo Gráfico da Informática. São Paulo: Futura, 2002.

FERNANDES, A. Fundamentos de produção gráfica para quem não é produtor gráfico. Rio de Janeiro: Rubio, 2003.
FRANCO, G. Como escrever para a Web. Traduzido por: Marcelo Soares. Texas: Knight Foundation, 2008. Disponível em: <https:// knightcenter.utexas.edu/como_web_pt-br.pdf $>$. Acesso em: 13 fev. 2018.

GILLETTE, M. Providing Clarity of Industry Terminology. Biomass Magazine, 29 mar. 2017. Disponível em: <http://www.biomassmagazine. com/articles/14275>. Acesso em: 26 abr. 2017.

HOHENDORFF, J. V. Como escrever um artigo de revisão de literatura. In: KOLLER, Sílvia H.; COUTO, Maria Clara P. de Paula; HOHENDORFF, Jean Von (Org.). Manual de produção científica. Porto Alegre: Penso, 2014. cap. 2, p. 39-54.

HORIE, R. M.; PEREIRA, R. P. 300 Superdicas de editoração, design e artes gráficas. São Paulo: Senac, 2004.

LEME, R. Mas o que são competências? In: Aplicação prática de gestão de pessoas por competências: mapeamento, treinamento, seleção, avaliação e mensuração de resultados de treinamento. Qualitymark, 2005. p. 13-19.

LOPES, A. W. S. Design e editorial. In: NICOLAU, Raquel Rebouças A. (Org.). Zoom: design, teoria e prática. João Pessoa: Ideia, 2013.

MARTINS FILHO, P. Manual de Editoração e Estilo. Campinas: Editora da Unicamp; São Paulo: Editora da Universidade de São Paulo; Belo Horizonte: Editora UFMG, 2016.

MEDEIROS, J.; VIEIRA, F. G. D.; NOGAMI, V. K. da C. A construção do mercado editorial eletrônico no Brasil por meio de práticas de marketing. Revista de Administração Mackenzie, São Paulo, v. 15, n. 1, p. 152173, jan./fev. 2014. Disponível em: <http:// editorarevistas.mackenzie.br/index.php/RAM/ article/view/5777>. Acesso em: 13 set. 2017.

OLIVEIRA, M. Produção gráfica para designers. 2. ed. Rio de Janeiro: 2AB, 2002.

PEREIRA, M. G. Artigos científicos: como redigir, publicar e avaliar. São Paulo: Guanabara Koogan, 2011. 
PERRENOUD, P. Construir as competências desde a escola. Porto Alegre: Artmed, 1999.

RUBI, M. P. Os princípios da política de indexação na análise de assunto para catalogação: especifidade, exaustividade, revocação e precisão na perspectiva dos catalogadores e usuários. In: FUJITA, Mariângela Spotti L. et al. (Org.). A indexação de livros: a percepção de catalogadores e usuários de bibliotecas universitárias. Um estudo de observação do contexto sociocognitivo com protocolos verbais. São Paulo: Editora Unesp; São Paulo: Cultura Acadêmica, 2009. cap. 4, p. 81-93. Disponível em: <http://books.scielo.org/id/wcvbc/pdf/ boccato-9788579830150-06.pdf>. Acesso em: 20 maio 2017.

SALES, L. F.; SAYÃO, L. F. Gestão de dados de pesquisa. 2017. Disponível em: <http:// www.cnen.gov.br/images/CIN/PDFs/CURSOSay\%C3\%A3o-DEZ2017.pdf>. Acesso em: 07 abr. 2018.

SANTANA, S. A.; FRANCELIN, M. M. O bibliotecário e a editoração de periódicos científicos. Revista Brasileira de Biblioteconomia e Documentação, São Paulo, v. 12, n. 1, p. 2-26, jan./jun. 2016. Disponível em: <https://rbbd. febab.org.br/rbbd/article/view/543>. Acesso em: 13 set. 2017.

SCIELO BRASIL. Critérios, política e procedimentos para a admissão e a permanência de periódicos científicos na Coleção SciELO Brasil. São Paulo: 2014. Disponível em: <http://www.scielo.br/ avaliacao/20141003NovosCriterios_SciELO_ Brasil.pdf>. Acesso em: 07 abr. 2018.

SOCIEDADE BRASILEIRA DE DESIGN DA INFORMAÇÃO. Sobre [a SBDI]. Disponível em: <http://sbdi.org.br/sobre>. Acesso em: 13 fev. 2018.

STEFANO, N. M. Critérios para avaliação da gestão de periódicos científicos eletrônicos sob a ótica do Capital Intelectual. 2014. 214 f. Tese (Doutorado em Engenharia da Produção) - Centro Tecnológico, Universidade Federal de Santa Catarina, Florianópolis, 2014. Disponível em: <https://repositorio.ufsc.br/ bitstream/handle/123456789/128666/327642. pdf? sequence $=1>$. Acesso em: 20 maio 2017 .

VIDOTTI, S. A. B. et al. Arquitetura da informação e eye tracking: o que o olhar e os dados revelam. In: ENCONTRO NACIONAL DE PESQUISA EM CIÊNCIA DA INFORMAÇÃO, 27., 2016, Salvador. Anais... Salvador: UFBA, 2016. Disponível em: <http://www.ufpb.br/evento/ 1ti/ocs/index.php/enancib2016/enancib2016/ paper/viewFile/4083/2551>. Acesso em: 13 fev. 2018.

VILLAS-BOAS, A. O que é [e o que nunca foi] design. Rio de Janeiro: 2AB, 1999. 